\title{
Human leukocyte antigen (HLA) diversity and clinical applications in South Africa
}

\author{
J Mellet, ${ }^{1} \mathrm{MSc} ; \mathrm{M}$ Tshabalala, ${ }^{1} \mathrm{MSc} ; 0$ Agbedare, ${ }^{1} \mathrm{MD} ;$ P W A Meyer, ${ }^{2} \mathrm{PhD} ; \mathbf{C ~ M}$ Gray, ${ }^{3,4} \mathrm{MSc}, \mathrm{PhD} ; \mathrm{M} \mathrm{S}$ Pepper, ${ }^{1} \mathrm{MB}$ ChB, $\mathrm{PhD}, \mathrm{MD}$ \\ ${ }^{1}$ Institute for Cellular and Molecular Medicine, Department of Immunology, and SAMRC Extramural Unit for Stem Cell Research and Therapy, \\ Faculty of Health Sciences, University of Pretoria, South Africa \\ ${ }^{2}$ Department of Immunology, Faculty of Health Sciences, University of Pretoria, and National Health Laboratory Services, Pretoria, South Africa \\ ${ }^{3}$ Division of Immunology, Institute of Infectious Diseases and Molecular Medicine, and Department of Pathology, Faculty of Health Sciences, \\ University of Cape Town, South Africa \\ ${ }^{4}$ Laboratory for Tissue Immunology, National Health Laboratory Services, Groote Schuur Hospital, Cape Town, South Africa
}

Corresponding author: M S Pepper (michael.pepper@up.ac.za)

The major histocompatibility complex, known as the human leukocyte antigen (HLA) complex in humans, forms an integral component of adaptive $\mathrm{T}$ cell immunity by presenting self and non-self peptides to the $\mathrm{T}$ cell receptor, thereby allowing clonal expansion of responding peptide-specific $\mathrm{CD}^{+}$and $\mathrm{CD} 8^{+} \mathrm{T}$ cells. HLA likewise forms an integral part of the innate immune response through the binding of killercell immunoglobulin-like receptor (KIR) molecules, which regulate the response of natural killer (NK) cells. The HLA complex is found on the short arm of chromosome 6 and is the most polymorphic region in the human genome. Africans are genetically more diverse than other populations; however, information on HLA diversity among southern Africans, including South African populations, is limited. Paucity of African HLA data limits our understanding of disease associations, the ability to identify donor-recipient matches for transplantation and the development of disease-specific vaccines. This review discusses the importance of HLA in the clinical setting in South Africans and highlights how tools such as HLA imputation might augment standard HLA typing methods to increase our understanding of HLA diversity in our populations, which will better inform disease association studies, donor recruitment strategies into bone marrow registries and our understanding of human genetic diversity in South Africa.

S Afr Med J 2019;109(8 Suppl 1)S:30-S34. https://doi.org/10.7196/SAMJ.2019.v109i8b.13825

The major histocompatibility complex (MHC), referred to as the human leukocyte antigen (HLA) complex in humans, is located on the short arm of chromosome 6 (Fig. 1). This region encodes cell surface proteins that form part of the innate and adaptive immune responses through binding killer-cell immunoglobulin-like receptor (KIR) molecules on the surfaces of natural killer (NK) cells and the recognition and binding of self and non-self peptides.

The HLA region is the most polymorphic region in the human genome. ${ }^{[1]}$ Allelic variants mostly arise within the nine classic genes (HLA-A, - $B,-C,-D P A 1,-D P B 1$, $-D Q A 1,-D Q B 1,-D R A$ and $-D R B 1)$ of the HLA region. Classic HLA molecules present peptides to the $\mathrm{T}$ cell receptor (TCR) of $\mathrm{CD}^{+}$and $\mathrm{CD}^{+} \mathrm{T}$ cells, while non-classic HLA molecules mediate inhibitory or activating stimuli. ${ }^{[2]}$ There are currently 21499 HLA alleles listed in the IMGT/HLA database (https://www.ebi.ac.uk/ipd/imgt/ hla/stats.html release 3.35.0 January 2019), of which 15586 are class I and 5913 class II alleles (Fig. 2). ${ }^{[3]}$

The class I HLA region spans $>2000 \mathrm{~kb}$ and consists of $\sim 20$ genes. There are three classic HLA genes within the class I region: $H L A-A,-B$, and $-C$. The HLA-B locus is the most polymorphic of the class I genes, ${ }^{[4]}$ with 5881 alleles currently documented in the HLA database, while HLA-A has 4846 and HLA-C 4654 alleles. ${ }^{[3]}$ The classic HLA class I genes consist of eight exons, while the polymorphisms reside in gene regions that encode the peptidebinding groove. Class I molecules consist of two chains, the a chain and non-covalently

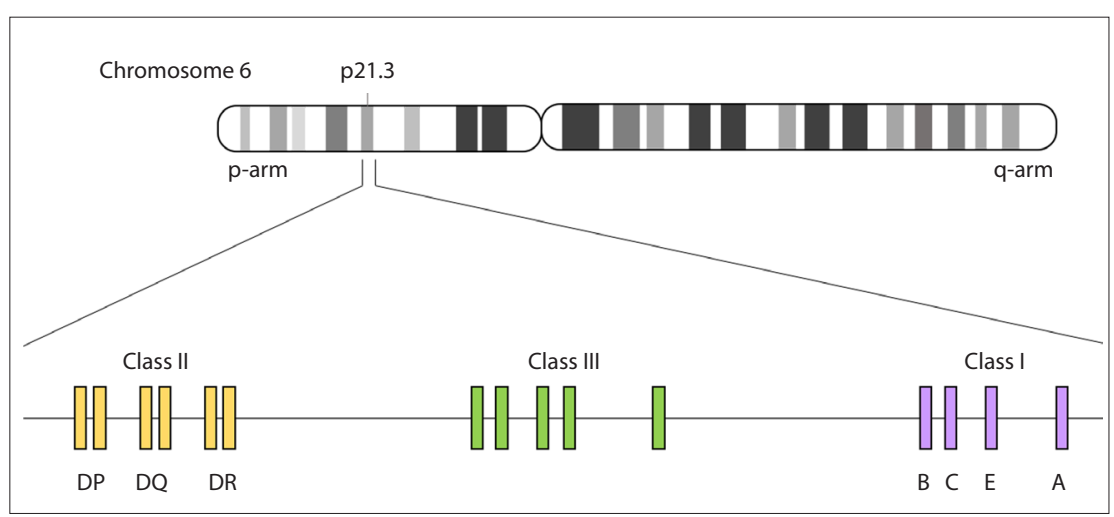

Fig. 1. The HLA region on chromosome 6. The HLA region is located on the short arm (p21.3) of chromosome 6 and spans $>3.6 \mathrm{Mb}$. This region comprises three classes (I, II and III) that play an important role in immune responses. 


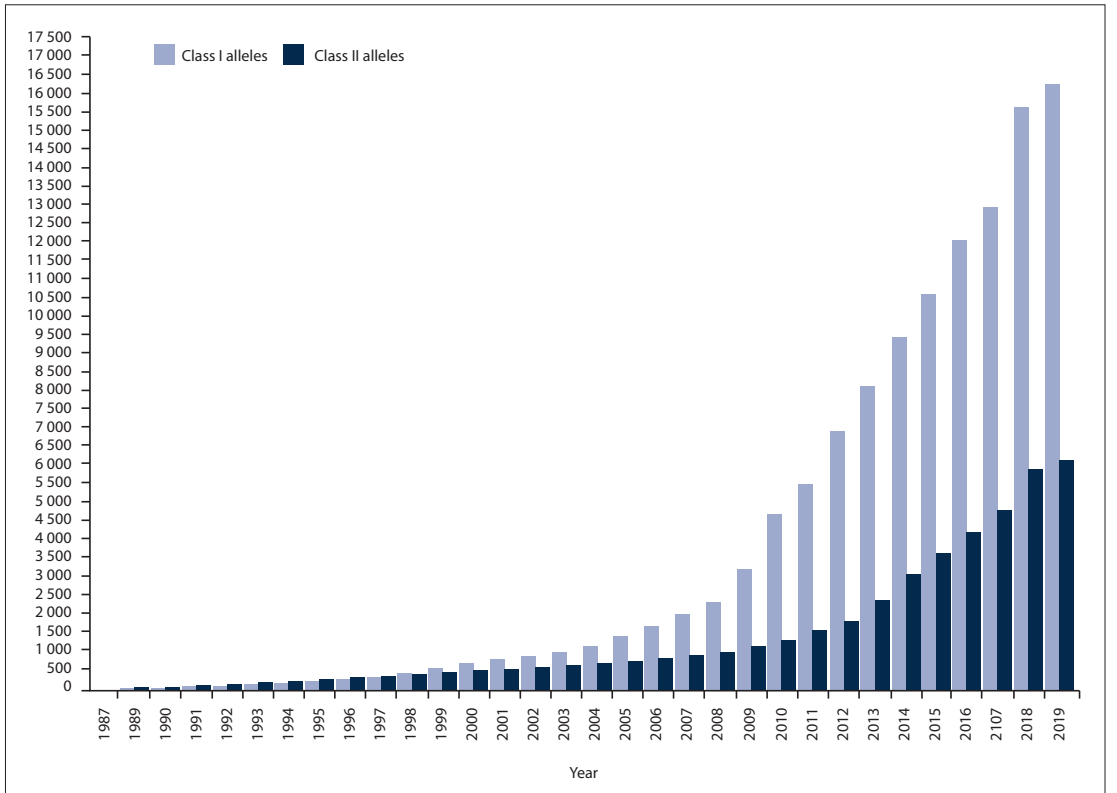

Fig. 2. The number of HLA alleles has been increasing since 1987 owing to advancement in typing methods. There are currently more than 14000 and 5000 class I and II alleles respectively in the IMGT HLA database (figure from http://hla.alleles.org/inc/images/graph_hires.png, accessed 23 April 2019). ${ }^{[3]}$

pathogens such as viruses. In addition, class I molecules are also recognised by KIRs which mediate tolerance and response of NK cells.

Class II molecules include the classic $H L A-D$ genes, which are subdivided into DQ (DQA1 and DQB1), DP (DPA1 and $D P B 1)$, and DR (DRA and DRB1), and are restricted to immune competent cells (B cells, macrophages, and endothelial cells of $\mathrm{T}$ cells). The class II genes encode proteins that are expressed on the cell surface of antigen-presenting cells (APCs), where they present peptides to helper $\mathrm{T}$ cells. Within the class II genes, exon 2 is the most variable region and also forms the peptide-binding groove. All class II molecules consist of two transmembrane chains: $\alpha$ and $\beta$ domains. The extracellular component of each class II molecule consists of two domains ( $\alpha 1, \alpha 2$ and $\beta 1, \beta 2$ ). The $\alpha 1$ and $\beta 1$ domains form the peptide-binding groove. Broadly, class II molecules are involved in the exogenous pathway and are associated with defence against extracellular pathogens such as bacteria. The TCR, which binds to the exogenously-derived peptide class II HLA complex, is found on $\mathrm{CD} 4^{+}$helper $\mathrm{T}$ cells.

The human immune system has evolved to interact with and mount immune responses against viral, parasitic, bacterial and other pathogen-derived peptides through high HLA diversity across populations. HLA needs to present an enormous array of antigenic peptides to $\mathrm{T}$ cells so that a unique immune response to a wide variety of peptides can be elicited.
The mechanisms that have been proposed to act on the evolution of HLA genes include: (i) accumulation of deleterious variants in nearby genes; ${ }^{[5]}$ (ii) gene conversion/ interlocus genetic exchange; ${ }^{[6]}$ (iii) overadvantage); ${ }^{[7]}$ and (iv) frequency-dependent selection. ${ }^{[8]}$ The HLA variability observed can also be the result of the presence of duplicated genes with similar or overlapping functions. ${ }^{[9]}$ This assumption is made on the basis of the observation that the HLA complex consists of genes with similar but not completely identical structure and function. The variants within these genes mostly arise in the form of single-nucleotide polymorphisms (SNPs) and have directed the allelic diversity observed today. ${ }^{[10]}$ The diversity of these molecules has occurred due to the presence of different alleles at a specific locus within a species. The alleles can differ from one another by an alteration at a minimum of one SNP. Several thousand allelic variants of the HLA genes have already been described, with many alleles being present at frequencies below $1 \% .^{[1]]}$ The variation observed is often populationspecific and accounts for the diversity among populations. ${ }^{[12]}$ The divergence rate of the HLA genes is due to the long history of independent haplotype evolution, where Africans (including South Africans) are considered to be genetically more diverse than other populations. ${ }^{[13]}$ This has been shown using several genetic markers ${ }^{[14-16]}$ including HLA genes. ${ }^{[17]}$ Interestingly, most dominant balancing selection (heterozygote
HLA gene families that exist globally are found in African populations. ${ }^{[18]}$

The presence of specific HLA alleles in black South Africans has recently been reviewed by Tshabalala et al. ${ }^{[19]}$ however, HLA typing data for these individuals remains limited. The under-representation of black South Africans in the South African Bone Marrow Registry (SABMR) accentuates the paucity of HLA typing data available for this population. There is therefore an increased need for HLA typing data in black South Africans.

\section{HLA typing methods}

HLA typing methods have evolved over time from phenotypic identity using serology to genotyping at high resolution using DNA sequencing technology. Serologybased methods identify HLA molecules to antigen level, with DNA methods being able to identify to protein level. Despite high resolution, sequencing-based typing (SBT) has limitations of usually typing certain exons within the HLA loci, thereby giving partial sequences of about $10 \%$ of the reported alleles. ${ }^{[20]}$ Clinical HLA typing laboratories rarely sequence exons/ introns outside the peptide-binding groove for transplantation matching, with the assumption that they are not directly involved in $\mathrm{T}$ cell allo-recognition. ${ }^{[21,22]}$ This assumption is supported by modelling HLA/ peptide/ TCR interactions, ${ }^{[23]}$ and studying allele-specific peptide repertoires ${ }^{[24]}$ and other allo-recognition studies. ${ }^{[25]}$ Ambiguous allele combinations arising due to heterogeneity limit resolution in SBT, making it difficult to accurately assign HLA alleles. It is possible to sequence the entire HLA gene region using current SBT methods, but at a very high cost and requiring specific expertise. Another potential source of ambiguity in SBT is the cis/trans assignment of DNA bases in a heterozygous sample. ${ }^{[26]}$ There have been advances in the use of next-generation sequencing (NGS) to improve coverage of HLA gene loci at high throughput, while at the same time reducing ambiguity associated with SBT. ${ }^{[27]}$ Challenges of NGS HLA typing include the high number of polymorphisms associated with this gene region, with most individuals having heterozygous genotypes for most alleles. Other problems arise from the high number of pseudogenes in this region and long indels which cannot be efficiently covered by basic sequencing. The complex nature of some loci makes reference-based alignment of NGS reads less reliable. ${ }^{[28]}$ To fully appreciate NGS HLA typing tools, there is a 
need for complete full-length HLA allele sequences in the reference database. ${ }^{[27]}$

\section{HLA imputation as a tool for better understanding HLA diversity}

There is an information gap regarding the extent of HLA genetic diversity among South African populations and southern Africans in general. ${ }^{[19]}$ Additionally, there are limited high-resolution HLA allele frequency data (except for HLA-disease associations) publicly available for the SA population. ${ }^{[11]}$ Advances in computational biology make it possible to impute HLA alleles at a high degree of accuracy by inferring them from surrounding SNP markers across the $\mathrm{MHC}$ region ${ }^{[29]}$ based on the high linkage disequilibrium (LD) within this region. ${ }^{[30]}$ Additionally, high-resolution (up to 8 digit typing) HLA genotyping from whole genome sequence (WGS) and whole exome sequence (WES) datasets is possible from existing resources. ${ }^{[31-34]}$ These tools borrow from existing genomic projects and studies to better understand HLA diversity in those populations. There are several efforts to understand genetic diversity in Africans and South African populations in general, including the Southern African Human Genome Programme (https://www.sahgp.org/index. php) ${ }^{[35]}$ H3 Africa (https://h3africa.org/), 1000 Genomes project (http://www.internationalgenome.org/), and the African Genome Variation Project (https://www.sanger.ac.uk/science/collaboration/ african-genome-variation-project). There are numerous other studies generating WGS, WES and SNP data from SA and African populations from which data for HLA imputation may be accessed. Several HLA imputation tools, including SNP2HLA, ${ }^{[36]}$ HLA Genotype Imputation with Attribute Bagging (HIBAG) ${ }^{[37]}$ and $\mathrm{HLA}^{\star} \mathrm{IMP}^{[38]}$ have been used to successfully determine HLA genotypes from SNP data. Despite the high imputation accuracy, these tools will augment, but not replace, routine HLA typing methods.

\section{HLA applications}

The role of HLA in the recognition of self and non-self peptides was first described 60 years ago. Since this discovery, there has been an increasing body of knowledge that emphasises the important role of HLA in basic and clinical immunology. The initial groundwork of the HLA complex was performed by Dausset ${ }^{[39]}$ in 1958, and earned him a Nobel prize in 1980. His work was based on antibodies detected in multiparous women and multitransfused patients which reacted against leukocytes of numerous, but not all, individuals. These alloantibodies were proposed to play a critical role in tissue transplantation. A primary application of HLA typing is donor-recipient matching for solid organ and haematopoietic stem cell transplantation (HSCT). HLA mismatching between a haematopoietic stem cell donor and a recipient could result in a higher risk of rejection and occurrence of graft vs. host disease (GVHD) in the transplanted recipient. Four-digit molecular typing and a minimum of 9/10 matched alleles at five HLA loci (HLA-A, $-B$, $-C,-D Q B 1$ and $-D R B 1$ ) between donor and recipient are imperative to ensure engraftment success following a bone marrow-derived HSCT. ${ }^{[40]}$ The degree of HLA matching between donor and recipient varies with the type of transplantation; solid-organ transplantation requires less stringent HLA matching than does HSCT. In South Africa, for example, $H L A-A,-B,-C$ and $-D R$ typing for renal allograft donor-recipient matching is not done at all centres, and is done more to precisely identify donor-specific antibodies (DSAs) to the kidney allograft. Pre-transplant DSAs would be a contraindication to a transplant, for example, or would indicate tailoring post-transplant immunosuppressive treatments. The increased longevity of grafts transplanted in accordance with lower HLA mismatched loci is well-known ${ }^{[4]]}$ and has been confirmed in a meta-analysis of over 480000 transplanted patients. ${ }^{[42]}$ HLA typing and consequent matching of HLA donor-to-recipient phenotype forms an integral part of the bone marrow graft allocation protocol internationally as well as in the SA transplantation fraternity. Among other criteria for patients awaiting transplantation, novel strategies are being employed to establish improved HLA matching between unrelated living donors and recipients.

Most studies focus on the immuno-regulatory role of HLA and its related diagnostic or disease-associated applications. HLA disease associations have been published from the onset of HLA typing, and the phenomenon of LD has resulted in a vast body of evidence that ties certain diseases to a given HLA genotype. However, with everimproving molecular techniques allowing high-resolution typing, not only are these associations strengthened but they have also allowed fine mapping of HLA loci and/or alleles as being either protective against or increasing susceptibility to a given disease. Identification and targeting of neo-antigens and immunopeptidomes in cancer is the most recent clinical application of HLA, and holds great promise for precision medicine. ${ }^{[31]}$

Several HLA alleles in South Africans have been identified as associated with protection against, or susceptibility to, a wide variety of diseases which include autoimmune diseases, infectious diseases, and drug-induced hypersensitivity (Table 1). Autoimmune diseases include coeliac disease (CD), rheumatoid arthritis (RA), diabetes mellitus, and various other diseases. Infectious diseases associated with HLA alleles include human immunodeficiency virus/acquired immune deficiency syndrome (HIV/AIDS) and tuberculosis (TB). Heterozygosity and certain HLA alleles confer protection in HIVinfected individuals; however, other alleles such as $H L A-B^{*} 35$ have been reported to increase susceptibility to HIV, and are associated with rapid progression to AIDS. ${ }^{[43]} \mathrm{A}$ recent study by Ramsuran et al. ${ }^{[44]}$ has shown that increased mRNA expression of $H L A-A$ leads to increased HLA-E expression, which results in increased NKG2Amediated NK cell inhibition which, in turn impairs targeting of HIVinfected cells, ultimately leading to impaired HIV control. Blocking of HLA-E:NKG2A-mediated inhibition is currently being explored in clinical trials as a possible treatment option for various diseases. In black South Africans, $H L A-D R B 1^{*} 01: 02$ and $H L A-B^{\star} 58: 01$ have been associated with hepatotoxicity during HIV combination antiretroviral therapy (cART) initiation in regimens containing nevirapine. ${ }^{[45]}$ This is of particular importance in the context of precision medicine.

In SA, most HLA disease association testing is being done for $H L A-B^{\star} 27$. The initiation of molecular typing techniques has shown $H L A-B^{\star} 27: 05$ to have the strongest association with ankylosing spondylitis. ${ }^{[46]} \mathrm{CD}$ has been shown to have a significant association with $H L A-D Q 2\left(D Q A 1^{*} 05 / D Q B 1{ }^{*} 02\right.$ allele groups) and HLA-DQ8 haplotypes $\left(D Q A 1^{*} 03 / D Q B 1^{*} 03: 02\right.$ alleles). More than $95 \%$ of $C D$ patients have $H L A-D Q 2$ and/or $H L A-D Q 5 .{ }^{[47]}$ The majority of work on HLA disease association has been on autoimmune diseases and especially RA. Scherak et al. ${ }^{[48]}$ reported the association of RA with HLA-Dw4 in 1980. New evidence suggests that RA is associated with RAA shared epitope sequences (positions $72-74$ ), modulated by amino acid sequences at positions 70 and 71 , resulting in six genotypes with low to high RA risk. ${ }^{[49]}$ The HLA-DR4 as well as the RAA sequence phenomenon has been well described in the black SA populations. ${ }^{[50]}$

There is a great need to develop and test vaccines that are specific for the diseases that affect southern African populations. The genetic diversity of pathogens together with the genetic diversity of HLA in 
Table 1. Summary of HLA-disease associations in South African populations

\begin{tabular}{|c|c|c|c|c|c|}
\hline & \multicolumn{2}{|c|}{ HLA class I } & \multicolumn{2}{|c|}{ HLA class II } & \multirow[b]{2}{*}{ References } \\
\hline & Susceptive & Protective & Susceptive & Protective & \\
\hline Ankylosing spondylitis & $B^{\star} 27$ & - & $\begin{array}{l}- \\
D Q 2\end{array}$ & - & 46,55 \\
\hline Coeliac disease & - & - & $\begin{array}{l}\text { DQ5 } \\
\text { DQ8 }\end{array}$ & - & 47 \\
\hline Graves' disease & - & - & $\begin{array}{l}D R B 1^{*} 01 \\
D R B 1^{*} 03\end{array}$ & 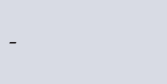 & 56,57 \\
\hline Rheumatoid arthritis & - & - & $\begin{array}{l}D R B 1^{*} 04: 01 \\
D R B 1^{*} 10\end{array}$ & $\begin{array}{l}D Q A 1^{*} 05: 01 \\
D Q B 1^{*} 06 \\
D R B 1^{*} 03: 01 \\
D R B 1^{*} 03: 02 \\
D Q A 1^{*} 01: 02\end{array}$ & $50,57,58$ \\
\hline Type I diabetes & $\begin{array}{l}B^{*} 08 \\
B^{*} 14\end{array}$ & - & $\begin{array}{l}D R B 1^{*} 03 \\
D R B 1^{*} 04\end{array}$ & $\begin{array}{l}D Q A 1^{*} 04 \\
D R B 1^{*} 03: 02 \\
D R B 1^{*} 06: 02 \\
D R B 1^{*} 11\end{array}$ & 57,59 \\
\hline HIV & $\begin{array}{l}B^{\star} 08 / 08: 01 \\
B^{\star} 18 / 18: 01 \\
B^{\star} 45 / 45: 01 \\
B^{\star} 51: 01 \\
B^{\star} 58: 02\end{array}$ & $\begin{array}{l}A^{*} 74 / 74: 01 \\
B^{\star} 13: 02 \\
B^{*} 44: 03 \\
B^{\star} 57: 03 \\
B^{\star} 58: 01 \\
B^{\star} 81: 01\end{array}$ & - & - & 60 \\
\hline Tuberculosis & $\begin{array}{l}A^{*} 01 \\
B^{\star} 08 \\
B^{\star} 27\end{array}$ & - & $\begin{array}{l}D R B 1^{*} 03 \\
D R B 1^{*} 13: 02\end{array}$ & - & 57 \\
\hline
\end{tabular}

these populations are necessary for the development and efficacy of HLA-based vaccines. ${ }^{[51]}$ The majority of HLA frequency studies have focussed on high-income countries, where the prevalence of most infectious diseases is low, ${ }^{[1,52]}$ while countries mostly affected by such diseases would benefit more from these types of studies. HLA frequency studies would need to be extended to lower-to-middleincome countries in order to get an idea of the most common HLA alleles present in populations affected by diseases such as HIV and TB, to name a few. Alleles that occur frequently could be grouped into supertypes and used as targets for vaccines. Supertypes are HLA groups that share peptide-binding specificity. Twelve different supertypes have been identified to date and have been shown to be effective in identifying and characterising $\mathrm{T}$ cell epitopes from a variety of different disease targets. ${ }^{[53]}$ Applying the concept of HLA supertypes to vaccines is promising, as supertypes would narrow the search for antigenic peptides that will bind the HLA alleles of a large proportion of the population. ${ }^{[54]}$ This knowledge would be particularly beneficial in populations with high genetic diversity, such as Africans.

\section{Conclusion}

South Africa has a high disease burden, including communicable (HIV, TB) and non-communicable (cancer, cardiovascular disease, obesity, diabetes) diseases (http://www.who.int/gho/mortality_ burden_disease/en/). There are limited HLA diversity data for South African populations, ${ }^{[19]}$ which affects our understanding of HLAdisease association, donor-recipient matching for transplantation, population genetics and population-specific vaccine design. In the present article, we have reviewed the importance of HLA and its clinical applications for South Africans. Furthermore, we highlight how tools such as HLA imputation might increase our understanding of HLA diversity in our populations. As access to NGS becomes easier and cheaper, more South Africans may have their HLA genotypes determined; this will better inform disease association studies, donor recruitment strategies in bone marrow registries, and our understanding of human genetic diversity in South Africa in general.

Acknowledgements. This research was funded by the South African Medical Research Council in terms of the SAMRC's Flagship Award Project (SAMRC-RFA-UFSP-01-2013/STEM CELLS), the SAMRC Extramural Unit for Stem Cell Research and Therapy and the Institute for Cellular and Molecular Medicine of the University of Pretoria.

Author contributions. JM: first author, substantial contribution to drafting the manuscript; MT: co-author, substantial contribution to drafting the manuscript; OA: co-author, substantial contribution to drafting the manuscript; PWAM: co-author, substantial contribution to drafting the manuscript; CMG: co-author, substantial contribution to drafting the manuscript; MSP: conceptualised the manuscript, substantial contribution to writing and drafting the manuscript and approved the final version.

Funding. None.

Conflicts of interest. None.

1. Norman PJ, Norberg SJ, Guethlein LA, et al. Sequences of 95 human MHC haplotypes reveal extreme coding variation in genes other than highly polymorphic HLA class I and II. Genome Res 2017;27(5):813-823. https://doi.org/10.1101/gr.213538.116

2. Yawata M, Yawata N, Draghi M, Little A-M, Partheniou F, Parham P. Roles for HLA and KIR polymorphisms in natural killer cell repertoire selection and modulation of effector function. J Exp Med 2006;203(3):633-645. https://doi.org/10.1084/jem.20051884

. Robinson J, Halliwell JA, Hayhurst JD, Flicek P, Parham P, Marsh SGE. The IPD and IMGT/HLA database: Allele variant databases. Nucleic Acids Res 2015;43(Database issue):D423-431. https://doi. org/10.1093/nar/gku1161

4. Mungall AJ, Palmer SA, Sims SK, et al. The DNA sequence and analysis of human chromosome 6. Nature 2003;425(6960):805-811. https://doi.org/10.1038/nature02055 
5. Lenz TL, Spirin V, Jordan DM, Sunyaev SR. Excess of deleterious mutations around HLA genes reveals evolutionary cost of balancing selection. Mol Biol Evol 2016;33(10):2555-2564. https://doi. org/10.1093/molbev/msw127

6. Takuno $S$, Nishio T, Satta Y, Innan H. Preservation of a pseudogene by gene conversion and diversifying selection. Genetics 2008;180(1):517-531. https://doi.org/10.1534/genetics.108.091918
s. 0 .

7. Takahata N, Nei M. Allelic genealogy under overdominant and frequency-dependent selection and Takahata N, Nei M. Allelic genealogy under overdominant and frequency-dependent sece
polymorphism of major histocompatibility complex loci. Genetics 1990;124(4):967-978.

polymorphism of major histocompatibility complex loci. Genetics 1990;124(4):967-978.
8. Borghans JAM, Beltman JB, De Boer RJ. MHC polymorphism under host-pathogen coevolution. Borghans JAM, Beltman JB, De Boer RJ. MHC polymorphism under host-pat

Immunogenetics 2004;55(11):732-739. https://doi.org/10.1007/s00251-003-0630-5
9. Satta Y, Mayer WE, Klein J. Evolutionary relationship of HLA-DRB genes inferred from intron Satta Y, Mayer WE, Klein J. Evolutionar
sequences. J Mol Evol 1996;42(6):648-657.

sequences. J Mol Evol 1996;42(6):648-657.
10. Robinson J, Guethlein LA, Cereb N, et al. Distinguishing functional polymorphism from random variation in the sequences of >10,000 HLA-A, -B and -C alleles. PLOS 2017;13(6):e1006862. https:// doi.org/10.1371/journal.pgen. 1006862

11. González-Galarza FF, Takeshita LYC, Santos EJM, et al. Allele frequency net 2015 update: New features for HLA epitopes, KIR and disease and HLA adverse drug reaction associations. Nucleic Acids Res 2015;43(Database issue):D784-788. https://doi.org/10.1093/nar/gku1166

12. Jin P, Wang E. Polymorphism in clinical immunology - from HLA typing to immunogenetic profiling. J Transl Med 2003;1(1):8. https://doi.org/10.1186/1479-5876-1-8

13. Disotell TR. Archaic human genomics. Am J Phys Anthropol 2012;149(S55):24-39. https://doi. org/10.1002/ajpa.22159

14. Chen YS, Torroni A, Excoffier L, Santachiara-Benerecetti AS, Wallace DC. Analysis of mtDNA variation in African populations reveals the most ancient of all human continent-specific haplogroups. Am J Hum Genet 1995;57(1):133-149.

15. Jorde LB, Watkins WS, Bamshad MJ, et al. The distribution of human genetic diversity: A comparison of mitochondrial, autosomal, and Y-chromosome data. Am J Hum Genet 2000;66(3):979-988. https:// doi.org/10.1086/302825

16. Zigtkiewicz E, Yotova V, Jarnik M, et al. Nuclear DNA diversity in worldwide distributed human populations. Gene 1997;205(1-2):161-171. https://doi.org/10.1016/S0378-1119(97)00408-3

17. Prugnolle F, Manica A, Charpentier M, Guégan JF, Guernier V, Balloux F. Pathogen-driven selection and worldwide HLA class I diversity. Curr Biol 2005;15(11):1022-1027. https://doi.org/10.1016/j. cub.2005.04.050

18. Cao K, Moormann AM, Lyke KE, et al. Differentiation between African populations is evidenced by the diversity of alleles and haplotypes of HLA class I loci. Tissue Antigens 2004;63(4):293-325. https:// the diversity of alleles and haplotypes of $\mathrm{H}$
doi.org/10.1111/j.0001-2815.2004.00192.x

19. Tshabalala M, Mellet J, Pepper MS. Human leukocyte antigen diversity: A Southern African perspective. J Immunol Res 2015;2015:746151. https://doi.org/10.1155/2015/746151
persition

20. De Santis D, Dinauer D, Duke J, et al. 16(th) IHIW: Review of HLA typing by NGS. Int J Immunogenet 2013;40(1):72-76. https://doi.org/10.1111/iji.12024

21. Bettens F, Schanz U, Tiercy J-M. Lack of recognition of HLA class I mismatches outside $\alpha 1 / \alpha 2$ domains by CD8+ alloreactive T lymphocytes: The HLA-B44 paradigm. Tissue Antigens 2013;81(6):414-418. https://doi.org/10.1111/tan.12102

22. Crivello $\mathrm{P}$, Lauterbach N, Zito $\mathrm{L}$, et al. Effects of transmembrane region variability on cell surface expression and allorecognition of HLA-DP3. Hum Immunol 2013;74(8):970-977. https://doi. org/10.1016/j.humimm.2013.04.014

23. Xiao Y, Lazaro AM, Masaberg C, et al. Evaluating the potential impact of mismatches outside the antigen recognition site in unrelated hematopoietic stem cell transplantation: HLA-DRBI ${ }^{*} 1454$ and DRB1*140101. Tissue Antigens 2009;73(6):595-598. https://doi.org/10.1111/j.1399-0039.2009.01245.x

24. Bade-Doeding C, Cano P, Huyton T, et al. Mismatches outside exons 2 and 3 do not alter the peptide motif of the allele group $B^{*} 44: 02$ P. Hum Immunol 2011;72(11):1039-1044. https://doi,org/10.1016/j. humimm.2011.08.004

25. Lauterbach N, Crivello P, Wieten L, et al. Allorecognition of HLA-DP by CD4+ T cells is affected by polymorphism in its alpha chain. Mol Immunol 2014;59(1):19-29. https://doi.org/10.1016/j. molimm.2013.12.006

26. Lind C, Ferriola D, Mackiewicz K, et al. Next-generation sequencing: the solution for high-resolution, unambiguous human leukocyte antigen typing. Hum Immunol 2010;71(10):1033-1042. https://doi. org/10.1016/j.humimm.2010.06.016

27. Gabriel C, Fürst D, Faé I, et al. HLA typing by next-generation sequencing - getting closer to reality. Tissue Antigens 2014;83(2):65-75. https://doi.org/10.1111/tan.12298

28. Major $\mathrm{E}$, Rigó $\mathrm{K}$, Hague T, Bérces A, Juhos S. HLA typing from 1000 genomes whole genome and whole

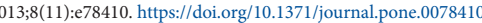

29. De Bakker PIW, McVean G, Sabeti PC, et al. A high-resolution HLA and SNP haplotype map for disease association studies in the extended human MHC. Nat Genet 2006;38(10):1166-1172. https:// doi.org/10.1038/ng1885

30. Leslie S, Donnelly P, McVean G. A statistical method for predicting classical HLA alleles from SNP data. Am J Hum Genet 2008;82(1):48-56. https://doi.org/10.1016/j.ajhg.2007.09.001

31. Hosomichi $K$, Shiina $T$, Tajima A Inoue I. The impact of next-generation sequencing technologies on HLA research. J Hum Genet 2015;60(11):665-673. https://doi.org/10.1038/jhg.2015.102

32. Bai $\mathrm{Y}, \mathrm{Ni} \mathrm{M}$, Cooper B, Wei Y, Fury W. Inference of high resolution HLA types using genome-wide RNA or DNA sequencing reads. BMC Genomics 2014;15:325. https://doi.org/10.1186/1471-2164-15-325 33. Ka S, Lee S, Hong J, et al. HLAscan: Genotyping of the HLA region using next-generation sequencing data. BMC Bioinformatics 2017;18(1):258. https://doi.org/10.1186/s12859-017-1671-3
34. Kawaguchi S, Higasa K, Shimizu M, Yamada R, Matsuda F. HLA-HD: An accurate HLA typing algorithm for next-generation sequencing data. Hum Mutat 2017;38(7):788-797. https://doi. argorithm for next-gen

35. Choudhury A, Ramsay M, Hazelhurst $S$, et al. Whole-genome sequencing for an enhanced understanding of genetic variation among South Africans. Nat Commun 2017;8:2062. https://doi. org/10.1038/s41467-017-00663-9

36. Jia X, Han B, Onengut-Gumuscu S, et al. Imputing amino acid polymorphisms in human leukocyte antigens. PLoS One 2013;8(6):e64683. https://doi.org/10.1371/journal.pone.0064683

37. Zheng X, Shen J, Cox C, et al. HIBAG-HLA genotype imputation with attribute bagging Pharmacogenomics J 2014;14(2):192-200. https://doi.org/10.1038/tpj.2013.18

38. Dilthey AT, Moutsianas L, Leslie S, McVean G. HLA*IMP - an integrated framework for imputing classical HLA alleles from SNP genotypes. Bioinformatics 2011;27(7):968-972. https://do org/10.1093/bioinformatics/btr061

39. Dausset J. Iso-Leuko-Antibodies. Vox Sang 1958;3(1):40-41. https://doi.org/10.1111/j.1423-0410.1958. tb03559.x

40. Caillat-Zucman S, Le Deist F, Haddad E, et al. Impact of HLA matching on outcome of hematopoietic stem cell transplantation in children with inherited diseases: A single-center comparative analysis of genoidentical, haploidentical or unrelated donors. Bone Marrow Transplant 2004;33(11):1089-1095. genoidentical, haploidentical or unrelate
https://doi.org/10.1038/sj.bmt. 1704510

41. Bradley BA. The role of HLA matching in transplantation. Immunol Lett 1991:29(1-2):55-59.

42. Shi X, Lv J, Han W, et al. What is the impact of human leukocyte antigen mismatching on graft survival and mortality in renal transplantation? A meta-analysis of 23 cohort studies involvin 486,608 recipients. BMC Nephrol 2018;19(1):116. https://doi.org/10.1186/s12882-018-0908-3

43. Ghodke Y, Joshi K, Chopra A, Patwardhan B. HLA and disease. Eur J Epidemiol 2005;20(6):475-488 https://doi.org/10.1007/s10654-005-5081-x

44. Ramsuran V, Naranbhai V, Horowitz A, et al. Elevated HLA-A expression impairs HIV contro through inhibition of NKG2A-expressing cells. Science 2018;359(6371):86-90. https://doi org/10.1126/science.aam8825

45. Phillips E, Bartlett JA, Sanne I, et al. Associations Between HLA-DRBI ${ }^{*} 0102$, HLA-B*5801, and hepatotoxicity during initiation of nevirapine-containing regimens in South Africa. J Acquir Immune Defic Syndr 2013;62(2):e55-57. https://doi.org/10.1097/QAI.0b013e31827ca50f

46. Simone D, Al Mossawi MH, Bowness P. Progress in our understanding of the pathogenesis of ankylosing spondylitis. Rheumatology (Oxford) 2018;57(suppl_6):vi4-vi9. https://doi.org/10.1093/ rheumatology/key001

47. Pallav K, Kabbani T, Tariq S, Vanga R, Kelly CP, Leffler DA. Clinical utility of celiac disease-associated Pallav K, Kabbani T, Tariq S, Vanga R, Kelly CP, Leffler DA. Clinical utility of celiac disease-ass
HLA testing. Dig Dis Sci 2014;59(9):2199-2206. https://doi.org/10.1007/s10620-014-3143-1

48. Scherak O, Smolen JS, Mayr WR. Rheumatoid arthritis and B lymphocyte alloantigen HLA-DRw4. J Rheumatol 1980;7(1):9-12.

49. Michou L, Croiseau P, Petit-Teixeira E, et al. Validation of the reshaped shared epitope HLA-DRB classification in rheumatoid arthritis. Arthritis Res Ther 2006;8(3):R79. https://doi.org/10.1186 $\operatorname{ar} 1949$

50. Meyer PWA, Hodkinson B, Ally M, et al. HLA-DRB1 shared epitope genotyping using the revised classification and its association with circulating autoantibodies, acute phase reactants, cytokines and clinical indices of disease activity in a cohort of South African rheumatoid arthritis patients. Arthritis Res Ther 2011;13(5):R160. https://doi.org/10.1186/ar3479

51. Prabdial-Sing N, Puren AJ, Bowyer SM. Sequence-based in silico analysis of well studied hepatitis C virus epitopes and their variants in other genotypes (particularly genotype 5a) against South African human leukocyte antigen backgrounds. BMC Immunol 2012;13(1):67. https://doi. org/10.1186/1471-2172-13-67

52. Ndung'u T, Gaseitsiwe S, Sepako E, et al. Major histocompatibility complex class II (HLA-DRB and -DQB) allele frequencies in Botswana: Association with human immunodeficiency virus type 1 infection. Clin Vaccine Immunol 2005;12(9):1020-1028. https://doi.org/10.1128/CDLI.12.9.10201028.2005

53. Sidney J, Peters B, Frahm N, Brander C, Sette A. HLA class I supertypes: A revised and updated classification. BMC Immunol 2008;9(1):1. https://doi.org/10.1186/1471-2172-9-

54. Ovsyannikova IG, Jacobson RM, Vierkant RA, Pankratz VS, Poland GA. HLA supertypes an immune responses to measles-mumps-rubella viral vaccine: Findings and implications for vaccine design. Vaccine 2007;25(16):3090-3100. https://doi.org/10.1016/j.vaccine.2007.01.020

55. Klemp P, Meyers OL, Du Toit ED. HLA-B27 and ankylosing spondylitis in African blacks. Arthriti Rheum 1982;25(6):716-717.

56. Omar MA, Hammond MG, Desai RK, Motala AA, Aboo N, Seedat MA. HLA class I and II antigen in South African blacks with Graves' disease. Clin Immunol Immunopathol 1990;54(1):98-102.

57. Lombard Z, Brune AE, Hoal EG, et al. HLA class II disease associations in southern Africa. Tissue Antigens 2006;67(2):97-110. https://doi.org/10.1111/j.1399-0039.2006.00530.x

58. Rousseau I, Pokorny L, Glaser J. Predisposing and protective HLA-DR and -DQ alleles for rheumatoid Rousseau J, Pokorny L, Glaser J.Predisposing and protective HLA-DR and -DQ alleles for rheu
arthritis in South African mixed-ancestry and Xhosa populations. S Afr J Sci 2003;99:89-91.

59. Hammond MG, Asmal AC, Omar MA. HLA and insulin-dependent diabetes in South African negroes. Diabetologia 1980;19(2):101-102.

60. Goulder PJR, Walker BD. HIV and HLA Class I: An evolving relationship. Immunity 2012;37(3):426 440. https://doi.org/10.1016/j.immuni.2012.09.005 